\title{
Family physicians support Open Pharma
}

\author{
Cite as: CMAJ 2017 July 10;189:E923. doi: 10.1503/cmaj.1095448
}

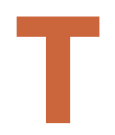
he College of Family Physicians of Canada (CFPC) has thrown its support behind the Open Pharma initiative and the Royal College of Physicians and Surgeons is considering it.

The Open Pharma campaign was launched in early June by a group of 12 health care providers, researchers and patient advocates. It calls on provincial governments to compel drug companies to release information about payments to individual doctors, and provide a database so that the public can look up any doctor and see if they're received money, how much and from what company. Public disclosure should extend to any gifts, money or other "transfers of value" to physicians, according to the group.

In addition, the campaign is calling for data from industry-funded research to be publicly available, along with all clinical information on the safety of drugs and devices approved by Health Canada.

"It's about patients being able to have all the information they need to make informed decisions, but it's also about physicians who rely on expert opinions," said Dr. Andrew Boozary, cofounder of the Open Pharma campaign and a resident at St. Michael's Hospital in Toronto. With the opioid crisis, for example, he said doctors may have made better decisions had industry-funded research data and the industry's payments to pain experts been widely available.

Given that much clinical research relies on some funding from industry, however, Boozary pointed out, "we're not saying that anyone who has received payments from pharma is not valued or shouldn't be used as an expert."

Dr. Francine Lemire, executive director of the CFPC, echoed this sentiment. "We are not suggesting that physicians should not have any relationships with industry...but if you have such relationships, declare them, and let the patients decide [if the relationship is an issue for them]."

This disclosure is already required in the United States, France, Scotland and Denmark. "It's important for Canada to follow suit," said Lemire.

The demands go beyond the other countries' transparency, however, with a request for complete datasets in industry-funded research to be available for reanalysis by other researchers. Boozary sure of payments initiative, 10 companies will voluntarily disclose payments to physicians as a whole, without revealing individual recipients.

But the CFPC said an aggregate number of amounts paid to physicians and health care organizations does not offer transparency.

The IMC framework "is an important first step," countered Paul Lirette, president

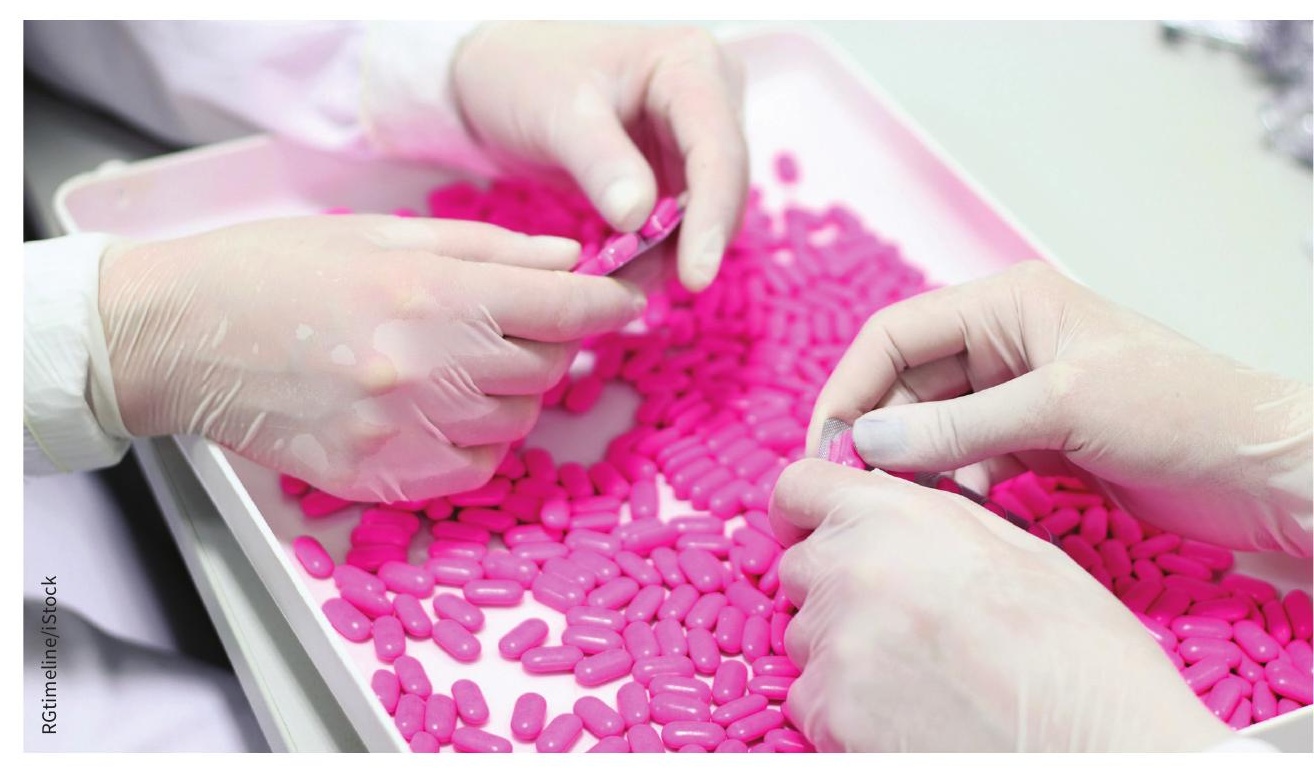

Family doctors support disclosing payments from drug companies to individual doctors.

points out that, otherwise, analyses can be done in "misleading" ways that "overstate the effectiveness of the treatment."

Meanwhile, the Royal College of Physicians and Surgeons, which accredits residency and continuing medical education programs for physicians, is "currently reviewing" the campaign, and "cannot comment on it in an interview at this time," said Melissa Nisbett, senior communications specialist.

In its statement supporting Open Pharma, the CFPC noted the inadequacy of another transparency initiative led by Innovative Medicines Canada (IMC), which represents brand-name pharmaceutical companies. Under the voluntary disclo- of GlaxoSmithKline Canada. He added that "more must be done to build confidence." Noting the company "appreciates" Open Pharma's proposal, he said, "Moving forward, Canadian governments, stakeholders and industry must work together to design and adopt mandatory, detailed disclosure requirements that are in-line with global standards."

In the coming months, Open Pharma campaigners hope to expand to include "different stakeholders from many different disciplines across the country," said Boozary.

Wendy Glauser, Toronto, Ont. 